\title{
Viewpoints: ShopArt ArtShop (SA AS) Art Project Modern Art meets Traditional Village
}

\author{
By Frank Schlichtmann \\ Gunehar, Himachal Pradesh
}

\begin{abstract}
The founder of the project Frank Schlichtmann was invited by the editor of the magazine to share his vision of the project in relation to the contemporary world of art. ShopArt ArtShop (SA AS) was started in 2013 with the aim of giving Indian artists the opportunity to relate to and work on arts in a wholesome manner outside the confines of usual, urban-centric art spaces. It is an inclusive, process-oriented conceptual arts event which takes place every 3 years in a small village, Gunehar, in the Indian Himalaya. The objective is to demonstrate openly the whole process of creating art from the inception of a concept to the creating of the actual art work.
\end{abstract}

\section{About Frank Schlichtmann}

German-Bengali Frank was born near Hamburg, Germany, and came to India for the first time when he was barely 4 years old and has been coming back to India on a regular basis. Before a set of coincidences would have him settle down permanently in Gunehar with his little son, Frank has worked and lived in 3 continents: Europe, Asia and America. He has been part of numerous projects related to the Arts, Culture and Hospitality but it was through his settling down in Gunehar and the founding of the 4tables project that he could start putting his vast experience into cohesive practice. Frank chose the village because of its relative 'unspoiltness' and also because he believes that in a truly globalized and interconnected world, a small village can be as valuable as any other place.

-Editor

The recently concluded second edition of the conceptual arts event, ShopArt ArtShop 2, held outside the confines of usual city-centric art spaces in a small Himachal village, caught the imagination of a broad public and the national media. It is a welcome indication that India's artists as well as art enthusiasts are hungry for innovative and holistic, process-oriented and open art concepts emanating from a parallel arts scene. At the same time, the empirical SA AS Method exposes some of the fault-lines of the art system. Here, Frank Schlichtmann, the founder and curator of the event, writes about the motivation for creating an event such as this as well as some of the outcome.

"The things themselves are not what science can reach... but only the relations between things. Outside of these relations there is no knowable reality." Henri Poincaré wrote in 1902.

"Creative minds say arts fight not only for funds, but relevancy."

"We say that dOCUMENTA (13) is dedicated to artistic research and forms of imagination that explore commitment, matter, things, embodiment and active living."

(c) AesthetixMS 2016. This Open Access article is published under a Creative Commons Attribution Non-Commercial 4.0 International License (http://creativecommons.org/licenses/by-nc/4.o/), which permits non-commercial re-use, distribution, and reproduction in any medium, provided the original work is properly cited. For citation use the DOI. For commercial re-use, please contact editor@chitrolekha.com. 
A lot has been said in the 99 years since Marcel Duchamp's tilting of a urinal by 90 degrees, but the controversy about the relevance of conceptual arts has not receded. While on the one hand Duchamp's 'Fountain' is considered one of the most influential artworks of the $2 \mathrm{o}^{\text {th }}$ century that "severed forever the traditional link between the artist's labour and the merit of the work" (The Independent, 2008), debates under the proposal "this House believes that conceptual art is no art at all" carry on.

What is surprising is that there is, even in 2016, no consensus when discussing conceptual arts or that, in India, it hardly enjoys any form of exposure. Maybe that is because nowadays, there is a mistaken assumption that all sorts of current art works belong under the banner of conceptual art. What is supposed to be a complicated and nuanced process has become a popularity contest among creators of "aha-effects'; but presentation, design, idea... these are more terms out of the bibles of entertainment, marketing and advertisement professionals than those offering new artistic perceptions. So, to host an event that requires of artists to live in an Indian village, engage with the people, spaces and traditions around them, work openly in front of villagers and visitors towards an exhibition that is acceptable both to villagers as well as connoisseurs of contemporary arts offers a welcome dose of contextual complexity, as does the fact that in this particular case, art is presented as a complete and inclusive process rather than just the presentation of finished art products. Art always needs context; the problem of the conceptual arts debate is that some do not recognize that art is, thus, always conceptual if it, in subtle ways, engages with contexts that otherwise appear simplistic and easily consumable.

To call a curiously titled art happening (ShopArt ArtShop) a conceptual arts event may raise some eyebrows, though it is not controversy the event seeks but rather the opposite. The CA label is not meant literally and can easily be sprinkled with a generous dose of Process Art and Art Povere. The play of words itself, ShopArt ArtShop, is a reflective criticism of a market oriented arts scene in which the salability and commercial value of artist's work seem so overwhelming that the utilization of empty commercial spaces in a little Indian village to open them as temporary artshops, far away from the usual art market, in itself is a manifest of sorts.

\section{Why A village?}

SAAS's primary goal is to create a holistic platform from which to address and analyze issues related to today's globalized world, especially questions of perception about our place in it. Secondly, it is a documentation of the art scene and artistic processes, this means not only that the focus is on particular artists and artistic disciplines but also that the whole event itself, from inception to the end, is a conceptual arts experiment. I personally find it meaningful to engage in this way with the emerging Indian art scene and believe that the attempt to determine the state of affairs is a necessary step towards developing new structures and creating appropriate thoughtspaces for the arts.

When SA AS was conceptualized in 2012, I did not realize that this is no small challenge, given that in India-despite a growing number of excellent artists as well as a blossoming arts infrastructure in the larger cities-- there are huge deficiencies both in art education, infrastructure for arts and artists, as well as the general perception of contemporary arts and its role in society. While researching the subject and during my efforts to engage other stakeholders from the art scene as well as trying to raise the money necessary to host the event, it had became clear that I was operating in a scenario which was unprecedented, and that simply inviting artists for an art 
exhibition would not be sufficient and that a broader, all-inclusive conceptual approach was a necessity.

As an outsider to the established art scene and someone who started living in rural India 9 years ago out of conviction, it was easy for me to place SA AS outside the mainstream arts infrastructure existent in India's cities. The idea is to host a truly contemporary art event in a village, which, in the global infrastructure, is the smallest denominating unit, and yet explore all possibilities of modern infrastructure to create an event not limited in its appeal to its geographic location. To have the audacity to treat a small Indian village as a legitimate space for contemporary experiments in arts elevates the importance of such a place and is an essential step towards the creation of a global community not based on a limited geographic identity.

So, SA AS has become a conceptual arts event in the broadest sense of the definition: it invites artists of all disciplines, through a screening process that determines their willingness and ability to relate to the generously multi-layered 'brief' set by SA AS, work in an inclusive manner, integrating the particular location, its infrastructure, logistical possibilities, its special narratives and sensibilities and rendering these into individual art projects, thus automatically transcending perceptional boundaries based on different living spaces and geographical location.

\section{Artists as interpreters}

The two major trends in arts in India that often dominates the mainstream discourse are both reactions to insecurities of the modern, globalised world. One is the constant re-discovering of the distant and not-so distant past. The other is an urge to interpret and comment on the state of the world. Both are insufficient and somewhat simplistic by nature. To believe that contemporary solutions can be found by re-imagining and re-interpreting the past is as banal as when artists becomes running commentators of actual events and believes that this will throw new light on existing problems. It might be fine for some artists to tread this path if their personal existential "Kampf is with systems that prevent their personal expression, but otherwise it merely becomes one more commentary in a sea of commentaries about "issues'. This is the kind of consternationart that appeals to the current international scene (that is itself in a crisis of identity) and, unfortunately, it's a compass to many new Indian artists.

In today's complex world we seem to desperately crave for a feel-good, entertaining spirit, which we expect to be provided by arts. But art is not a branch of the entertainment industry; it, rather, should help us escape preconceptions and the urge to offer easy, digestible, entertaining solutions. Unfortunately, we often do not have much patience for nuances and complexities; what 'goes', as a renown gallerist once told me, "is a generous dose of humor paired with the right amount of political concern, some depth... and, of course, talent”. Presumably, these elementary 'qualities' and mastery in manipulating abstract narratives, without actually having to physically and mentally live through processes, is enough to catch the imagination of an increasingly elitist and secluded art scene. The question the art scene has long stopped answering is about it's relevance. Who are we talking to? Who is art for? How can art reach out to a diverse public and be an effective mean of communication?

Art is the unique method of an artist struggling to frame questions and attempting to find answers within him/herself. We do not want an artist to lecture us about the world in general but about his/her struggle to make sense of it through his/her work. This is why artists need to be 
encouraged, through process-oriented conceptual events like SA AS, to work towards more nuanced, complex and courageous narratives and demonstrate the struggle openly to the world.

For an artist to find his/her way through the discrepancy between the very humane urge to communicate in his/her very unique way and define his/her unique place in this world and yet also navigate the 'market' and 'trends' just to remain in the public eye and yes, make a living, was always difficult and has become more so despite the grandiose sums being offered to a select few. This is particularly so in India, where a self-congratulatory and state-sponsored elitist clique has for decades manipulated the discourse (and kept it apart both from the larger public as well as from international scrutiny), hindering the real development of 'contemporary' arts and preventing the truer artists from breaking out and breaking boundaries. The result is that despite there being a huge pool of talent in this country, artists who indulge in conceptual disciplines can not find many opportunities to learn, work and prove themselves due to an acute lack of encouraging and nurturing infrastructure.

\section{Experimenting with the putting together of rural and urban Indians: villagers and artists}

Perched high on the southern slope of the Dhauladhaar Mountains, Gunehar is a village of Gaddis and Bara Bhangalis, people whose actual homeland is in the deep interiors of the Himalayas. Traditionally, the inhabitants of Gunehar would spend the summer months in their original villages and the winters in Gunehar. Essentially, Gunehar is borderland for these people.

The people of Gunehar are aware of a history and culture that has been distinct for centuries to the main culture of the plains in North India. In their own language, the word Jhandar defines this ambivalence: on the one hand it simply means "place down there" (i.e. the south), yet it can also mean "the exciting place' or "the dangerous place". In today's intermingled Indian identity, this characterization of the world beyond the interiors of the mountains that is their home and also 'safe zone' does not seem to mean much anymore. Yet if we look deeply, we can still find in places like Gunehar the uniqueness of habits, language and culture that defines their otherness.

We who come into their lives from the Jhandar tend to either romanticize them for their seminomadic life styles, their unique costumes and so on, or pity them as 'tribals" which promotes a myth of primitive timelessness, obscuring history and change. Noticeable, too, is a recent exploitation of tribal arts primarily by the established art scene. For us, 'intervention' has become a key word whenever we associate with them: we presume our knowledge and abilities are superior to theirs and we have something to tell them, something to give. In most conversations I have had to the lead up to this, and the first event in 2013, the main concern of the city people was "how is the village profiting from this?" Because if the villagers already have good water supply, electricity and food, why do they need an arts project? Is that not a waste of effort? After all, there are predestined spaces for this kind of thing in cities-- galleries, museums and such!

At SA AS, every interaction between villagers and artist is a transcending of such and other intellectual limitations; the methodology of the project is carefully tuned to make maximum interaction a necessity. When artists come with concepts of analyzing, redefining, amplifying and rendering the living conditions of villagers (for their arts) but find that they themselves are under the spotlight, their every move being watched by villagers and documented by SA AS, it leads to a rethinking and reversing of preconceived notions (not only about the relationship between the rural and the urban, but also about the ability of the artist to transcend these-or any-- 
'distances'). Some have felt uncomfortable at this: it shifts roles, but generally the reaction of most artists, and the results of their work at SA AS, have been extremely positive.

Similarly, a villager's perception of what is modern and contemporary outside of his/her usual domain is tested when usually urban artists take up 'shop' among their midst, becoming for a certain time part of their lives, working daily in front of them and integrating the daily experience they make and knowledge (of the village) they gain into pieces of art works that are no longer mysterious to them. This has the additional benefit of giving them pride because of being the center of attention and been taken seriously as what they are, rural Indians at the threshold of modernity, as middle class as anyone else.

\section{The SA AS Method}

SA AS believes that if the concept is clear and openly implemented, it enables the observer to relate to the arts in a wholesome way rather than just technically or aesthetically and also, it takes arts out of its otherwise elitist and secretive spaces to open it up to a larger public. To achieve this, a method has been devised which we call the SA AS Method. For artists who are interested in being part of SA AS, this is somewhat of a terms of agreement. We as SA AS insist that anybody who joins us follow this brief meticulously because it enables a kind of empirical research into larger themes.

The Brief states that artists need to be aware of and understanding of global contemporary art trends, uncompromising in their work, integrative of rural folks/villagers and local themes in their work, incorporate local materials and methods in their work and above all, be able to transcend, through their work, all three levels: rural-India, urban-India and the global. It is stated that we see the artists at the center of events and the process that goes into creating art "under the given circumstances" as our main objective, but also that the artists are required to create works that uphold critical scrutiny by a diverse public including art critics. This, admittedly, is a tall order, but as in many cases during both editions, it was a challenge many artists willingly faced, going through the month-long process enthusiastically. The feedback has been that they have seldom encountered such a nurturing and wholesome atmosphere to work in.

SA AS, while choosing artists, emphasizes three necessary objectives: demonstrating the thinking/conceptual process before the artist arrives in the village, demonstrating the actual work process in the village, including managing logistics, organization and time, and the demonstration of the artistic process each step of the way. Given that art, and particularly conceptual art can often come across as mysterious and even untrustworthy, transparency is immensely important, and we have taken the initial steps to put this whole documentation online for anyone to follow-- www.shopartshop.com/village (though at this stage shortly after the event we are still sitting on a huge amount of data that needs to be evaluated and archived).

To make the process transparent and accessible on the ground, SA AS artists need to go through certain rituals: choosing a shop to work in, negotiating with the landlord, setting up work-space in it, choosing a shop name and hanging out a sign board and keeping the shop open daily to use the space for the project as well as for interaction with villagers and visitors. The objective is that at any stage of the development of a project, one is open to scrutiny and forced to explain the ideas and motivation behind the work, thus practically demystifying artistic processes and making it accessible. 
One point of our 'unique features' is "The artist is at risk of failing", which is, given the open nature of the whole process, always a possibility and creates an interesting sub-context. But this article is not about the individual artists and their individual projects and a deeper evaluation of these must be done in some other place and time.

\section{So where do we go from here?}

With the first two editions of SA AS we have been able to come a long way towards realizing our overall objective, which is to establish an extraordinary art event that enables us to study the Indian art scene, establish certain important parameters and enable emerging artists to utilize the methodology and space we have created. The inclusive and multi-layered definition of arts has unvailed the immense potential that art can offer through subtle and nuanced ways of interpretation and communication. Questions about relevance and 'meaning' of arts have been addressed and ways shown out of a dilemma that the market-oriented and elitist art scene faces by utilising the entire field of creative possibilities and opening up the processes to a wide public indiscriminately. A large interested viewership has been created and immense media interest generated. All this has been done from a small village, using the infrastructure available, and with very little money. This is no mean feat.

Yet, what is also important is to reflect upon and be aware of the pitfalls that we have had to tediously avoid. Many things we have encountered and fended off have led to a reflection about the coherent state of corruption (for lack of a better word) that underlies every creative attempt to do things in this country. We have experienced that stakeholders can be engaged if we give up our autonomy, that money can only be raised by inflating budgets, that media can be bought, that big-name artists can be involved if we compromise on our method and let their names dominate the narrative. In general, the struggle to keep the event true to its objectives was not an easy one because it was was implied that 'being professional' meant all of the above.-- Throughout most of these experiences the one thing that has kept us motivated is the understanding that all these are part of our mission to document the state of affairs.

Two successful events have put the spotlight on SAAS, but also on the mainstream art scene. This is a responsibility for us to continue in our work and not fall pray to primary market forces, but it is also an opportunity for the mainstream to evaluate some of our findings and support our efforts. I believe our current art scene requires certain readjustments and that this movement has to come from the parallel art scene and such events as SA AS.

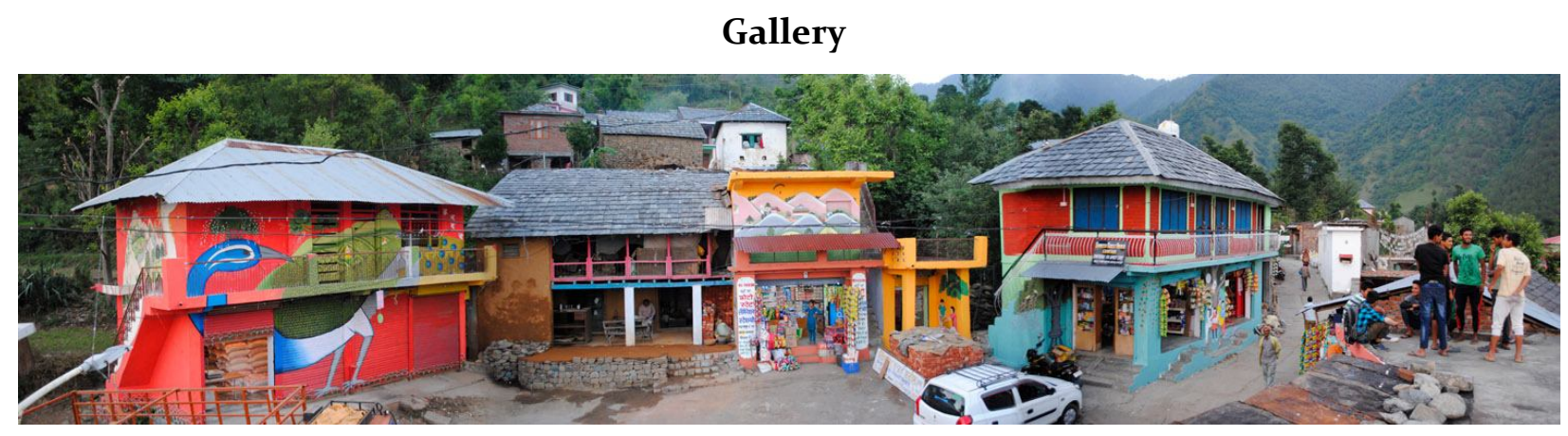

Figure 1: Market Square 


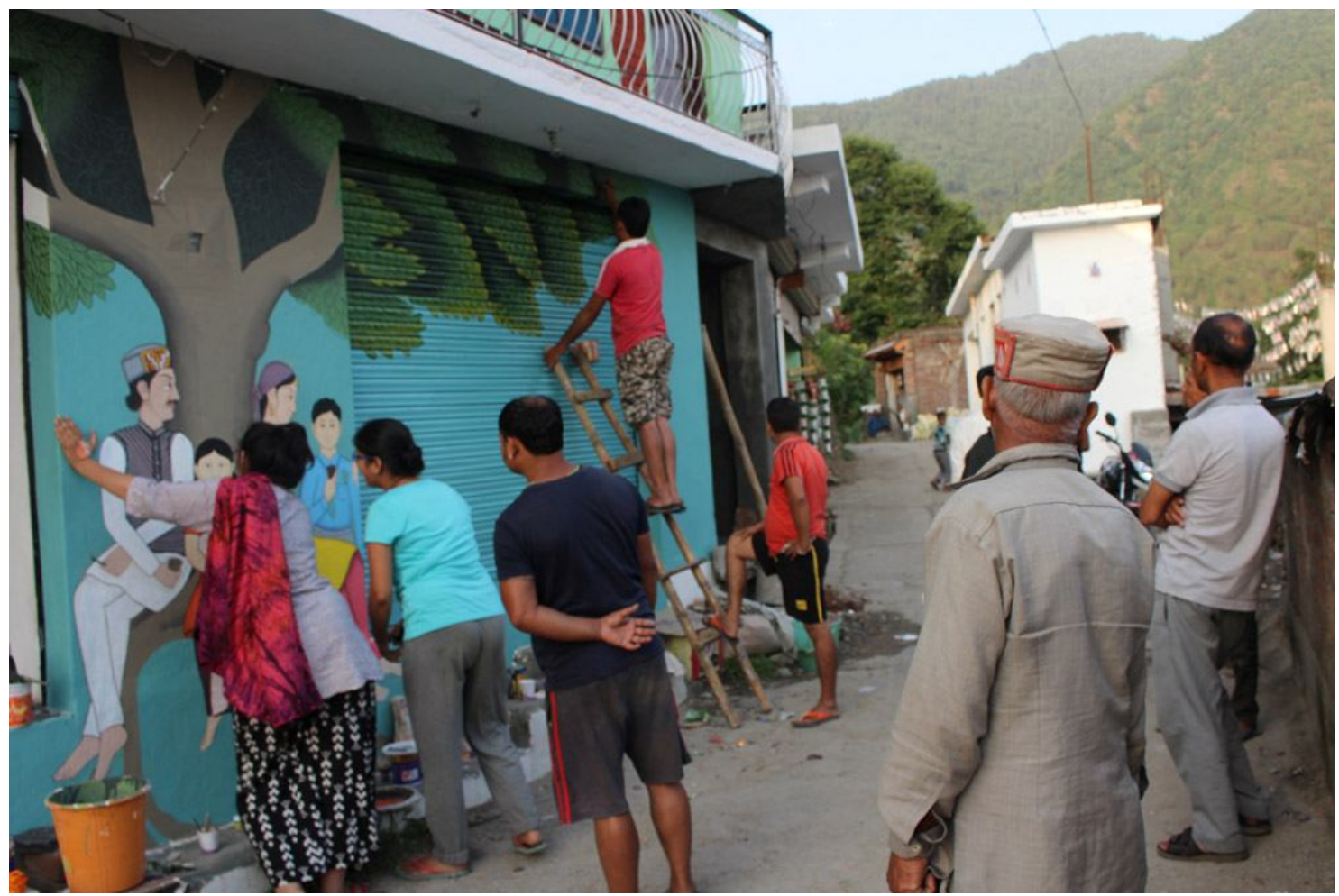

Figure 2: Graffiti being painted at Market Square

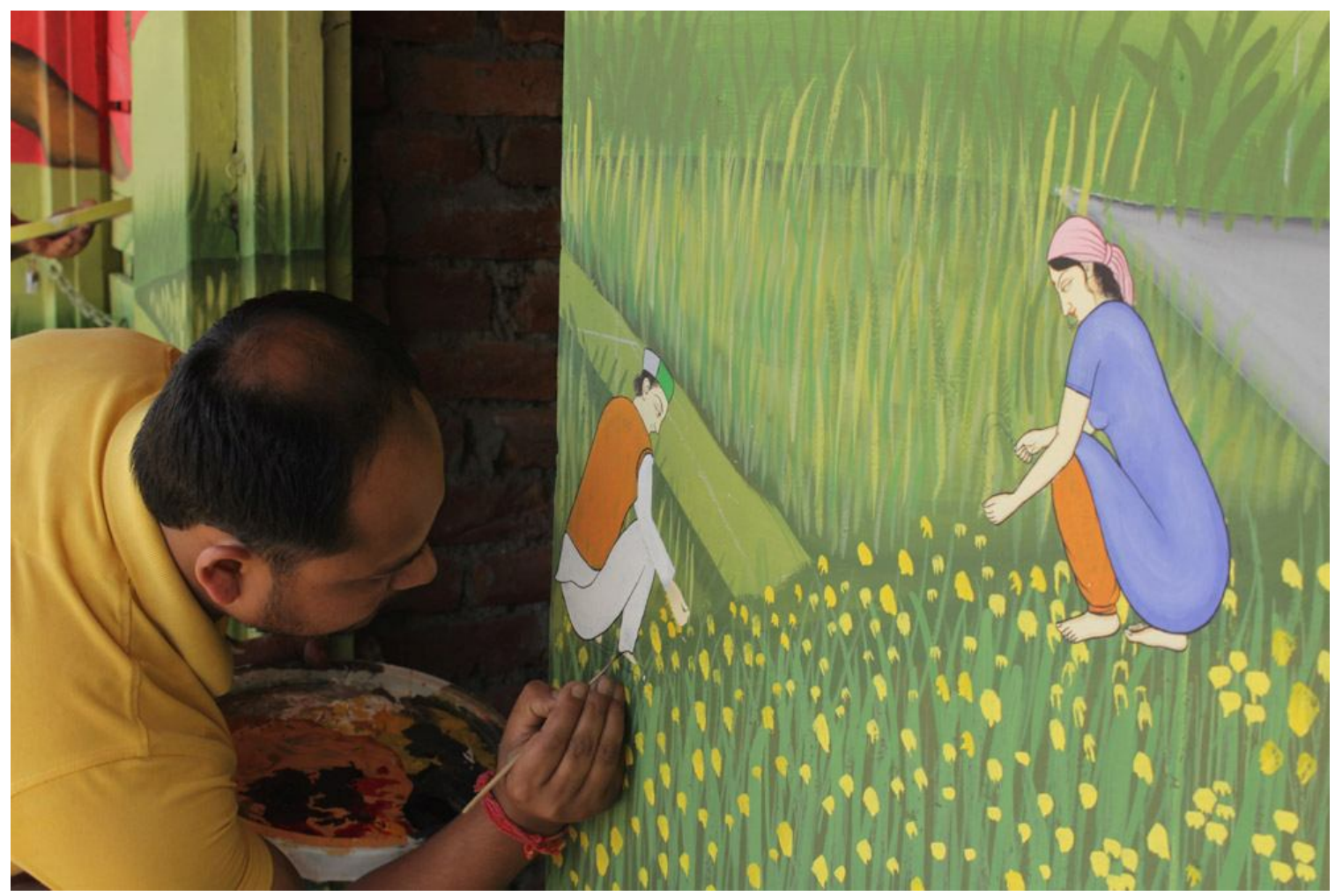

Figure 3: Kangra Miniature Painting 


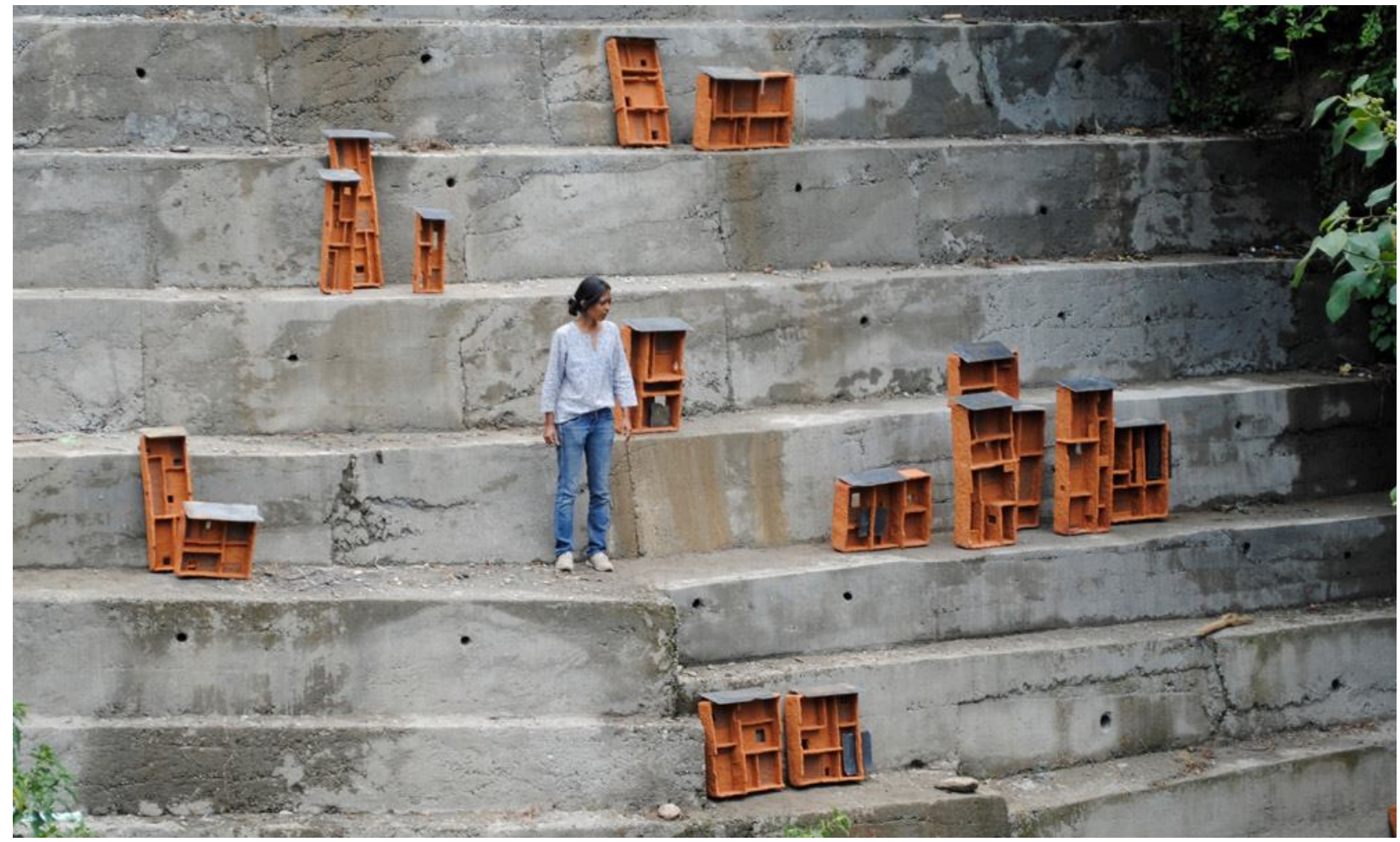

Figure 4: Public installation, Mudita Bhandari's Terracotta Space

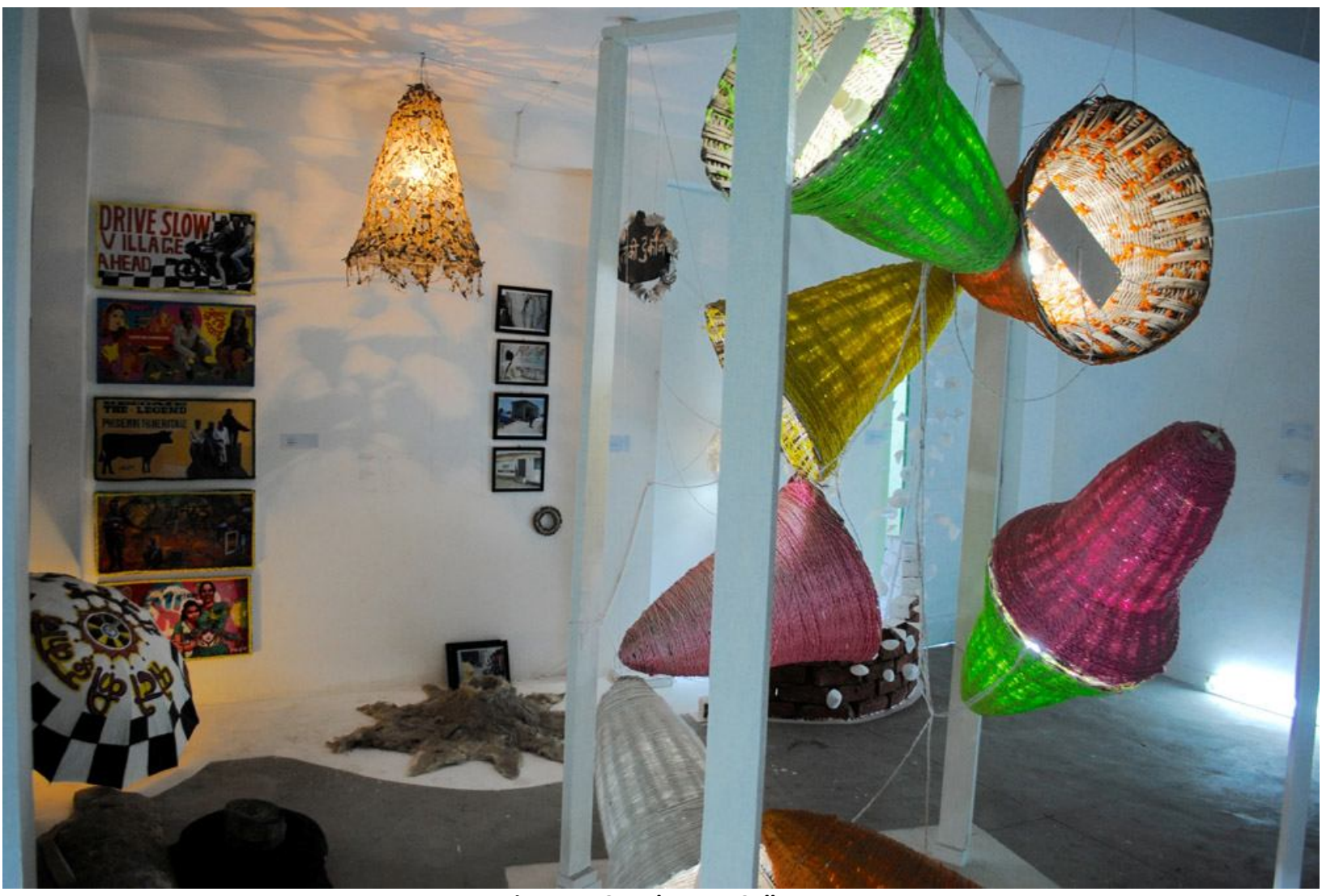

Figure 5: Gunehar Art Gallery 